\title{
LO ANGÉLICO Y LO POSTHUMANO: Encuentro de contrarios en el Ángel Caído de Marina Núñez
}

\author{
Nieves Acedo \\ Universidad de Navarra
}

Resumen: El presente texto analiza los múltiples temas que se encuentran en la serie de infografías Ángel Caído que la artista Marina Núñez expuso en la Catedral de Burgos en 2008. En estas obras, cuestiones propias del imaginario de la artista como la ciencia ficción, el feminismo y el transhumanismo se ven afectadas por la fuerza iconográfica y temática de la tradición de la representación angélica. En la primera parte se hace una breve presentación de la obra de la artista para pasar, en la segunda, al estudio de la serie en cuestión como lugar de encuentro entre aspectos propios del humanismo y de la teología judeo-cristiana con preocupaciones propias del cientifismo materialista.

Palabras clave: Marina Núñez, Ángel caído, ícaro, híbrido, transhumanismo, posthumanismo, arte y tecnología, iconografía cristiana.

The Angelic and the Posthuman: Encounter of Opposites in the fallen Angel of Marina Núñez

Abstract: This paper analyzes the multiplicity of issues addressed by the artist Marina Nuñez in her works Fallen Angel, a series of infographics exhibited at Burgos Cathedral (Spain) in 2008. In these works, typical topics of her art such as science fiction, feminism and transhumanism are shaken by the iconographic and thematic strength of the angelic images tradition. First, there is a brief presentation of the artist's work; secondly, the study of the series in question as a meeting point for humanism and Judeo-Christian theology aspects with some materialistic scientism concerns. 
Keywords: Marina Núñez, Fallen Angel, Icarus, Hybrid, Transhumanism, Posthumanism, Art and technology, Christian iconography.

Recibido: 25/5/2017 Aceptado: 10/6/2017

Con frecuencia los hitos del pensamiento surgen en la historia en forma de visión. Las iluminaciones profanas, como las llamaría Benjamin, tienen la fuerza e inmediatez de lo imaginativo. La auténtica metáfora comparece en la mente del poeta-profeta como algo inmediatamente visto. Podría ser que la visión preceda siempre al discurso, que el entendimiento no haga sino argumentar lo ya visto, tratando de poner a prueba su racionalidad. Y sería normal, porque el molino de la filosofía muele con frecuencia trigo de otros campos. Como el campo del arte visual, donde la imagen misma es catalizador de ideas aun no desplegadas. Se puede pensar la imagen artística, se puede también pensar el modo en que la imagen artística "piensa" (imagina) los temas comunes, las preocupaciones de un tiempo. Lo que la literatura, el cine, la arquitectura... muestran es lo que la filosofía estudia. Por eso considerar las cuestiones tal como aparecen en el estadio pre-discursivo o postdiscursivo, según los casos, de la imagen artística es un buen modo de pensar lo cultural.

Creían los medievales que era posible hacer una lectura unívoca de lo visual. Que se podía leer en el libro de la naturaleza, desarrollar repertorios de símbolos o inventar bestiarios para mostrar lo invisible. Toda una sociedad iletrada comprendía el valor asignado en común a cada imagen, objeto unánime de devoción o maravilla, de escarnio, de prohibición o de escándalo, según los casos. El rico mundo imaginativo medieval contrasta en esto con nuestra sociedad de la imagen. No sólo la reproducción incesante en innu- 
merables formatos, sino la vertiginosa transformación, ampliación y ramificación de los temas hacen posibles las vinculaciones más inverosímiles y complican tremendamente las labores de interpretación. La invasión de imágenes diversas capaces de todas las ambigüedades desborda nuestra habilidad analítica y hace inviables los repertorios. Lo visual se convierte en objeto de ciencia humana e incluso para los artistas parece que no tiene sentido ya imaginar nuevas formas. Es suficiente jugar desplazando valores o intentando acertar con los mecanismos de lectura más adecuados a cada caso. Una vez más en la historia, los creadores se vuelven arqueólogos, estudian el pasado visual para comprender el presente, analizan patrones, desvelan arquetipos y recuperan formas que son constantes pero que, de tanto en tanto, el afán por lo nuevo quiere ocultar.

El presente texto estudia el caso de las visiones del Ángel Caído que la artista Marina Núñez desarrolló para la exposición Luz y tiniebla en la Catedral de Burgos en 2008. Se trata de imágenes que constituyen un caso interesante de iconografía clásica adaptada a una sensibilidad contemporánea, que además se muestra en el marco de una catedral gótica y por encargo de un cabildo. El objetivo será analizar de qué modo y hasta qué punto las formas escogidas mantienen adherencias de visiones del mundo en gran parte pretéritas que aportan elementos valorativos o emocionales a su nueva configuración. 


\section{Utopía distópica}

El trabajo de la artista Marina Núñez (Palencia, 1966) conjuga la tradición visual de la cultura occidental y el interés contemporáneo por la biotecnología y la transformación de lo humano; pone en relación el evolucionismo transhumano de corte feminista con nuestra herencia pictórica; aborda desde la exploración de las nuevas tecnologías audiovisuales el desarrollo de un imaginario surreal inspirador de fantasías literarias.

La artista, que compagina la producción artística con su trabajo como profesora titular de pintura en la Universidad de Vigo, es una gran lectora y conocedora de la teoría y la historia del arte. Sus obras, aunque de enorme carga simbólica, no son en absoluto una mera ilustración de conceptos. Por el contrario, nacen de un trabajo eminentemente plástico y visual. De hecho, los aspectos conceptuales de su trabajo generalmente no se adaptan del todo bien a las teorías del feminismo, del transhumanismo o a la literatura más reciente de ciencia ficción, que indudablemente conoce bien, sino que emergen de la imagen y en coherencia sólo con ella.

Sin un programa predeterminado - afirma Barbara Rose-, las imágenes parecen ensamblarse conforme brotan del subconsciente de la artista, con un poder que estriba precisamente en su falta de cálculo y en la intensidad con la que expresan esas ansiedades y preocupaciones que reprimimos en este momento de cambio drástico en las relaciones entre los humanos, la naturaleza y la máquina. (Rose, 2010: 70). 
Es característico de su obra que su aproximación a los temas de la ciencia ficción, de lo distópico en cine y literatura y del pensamiento feminista se hace siempre en diálogo intenso con la tradición del arte occidental. La utilización de formas y símbolos heredados del pasado humanista permite evaluar en su trabajo las resistencias que las propias imágenes presentan a su reconfiguración artística, de modo que ejemplifica la exuberancia esencial a lo visual, en contraste con la reducción conceptual a la que la imagen se resiste. La idea de mutación que es constante en la obra de esta artista se soporta así en la propia potencia metamórfica de la imagen.

Las obras con las que Marina Núñez comienza su carrera pictórica en los primeros años 1990 son coherentes con preocupaciones propias de las teorías posmodernas entonces en boga. En series sobre lo siniestro y lo monstruoso reflexiona acerca de cómo el lenguaje y la ideología generan identidad. Su interés por el psicoanálisis y por la obra de Foucault aparece, por ejemplo, en sus Sin título. Locura (desde 1995), serie de obras que supone una reinterpretación pictórica de las fotografías de Charcot en la Salpêtrière. Como muestra de su gusto por el juego visual y de su diálogo consciente con la historia del arte, los óleos de Núñez hacen explícita la deuda con la iconografía cristiana que estaba latente en las fotos de Charcot (Mayayo, 2007).

En su serie Monstruas (1997), Núñez aborda el tema del descubrimiento del carácter mutante del propio cuerpo en pinturas de mujeres anónimas, solitarias, que parecen ser observadas como animales en un laboratorio y que se vuelven con mirada consciente, tímida o desafiante, hacia la curiosidad ajena. Los encuadres en picado convierten al espectador en científico que observa los cuerpos-naturaleza de estas mujeres, en los que las propiedades 
de la carne se transmutan y se deshacen, se funden o se amplían. Se trata de cuerpos blandos, maleables, en evolución continua. Lo ajeno o lo otro se incorpora a lo humano y obliga a redefinir la identidad, desafiando nuestra moderna capacidad de establecer taxonomías.

El cuerpo es campo para Marina Núñez, lugar en el que conocer los resquicios, los desajustes que revelan la "locura" o lo "monstruoso".

Durante esos primeros años el medio de Núñez es la pintura. Su pericia técnica y su alta cultura pictórica le permiten el diálogo visual con modos clásicos de representar. La artista no pinta el mundo, sino que recrea y reinterpreta, pintándolos de nuevo, los patrones visuales de nuestra cultura. Se sirve de la cita y del fragmento de un modo peculiar que busca desvelar, en lo familiar, lo siniestro.

Parece sin embargo que el dominio de su dibujo acaba por convertirse en una carga. La pintura como técnica, seguramente porque no le suponía ningún reto, le deja de servir. Pronto, el interés por la imagen de nuestro entorno visual la lleva a buscar otros medios, especialmente el vídeo. Se interesa así por la imagen en movimiento, no con el fin de introducir narrativa, sino para completar sus escenas de un modo que la imagen estática no le permite. Sus vídeos, de hecho, introducen movimiento, no narración: se miran como se mira un cuadro.

A partir de entonces Núñez empieza a trabajar con software propios de la industria del cine y los videojuegos. $\mathrm{Si}$, cuando pinta, la propia técnica introduce la historia de la pintura en sus obras, en la utilización de software de animación se advierte mucho de la estética que dejan en ellos sus desarrolla- 
dores. Esto coincide con sus intereses, que pasan del mundo de la locura y los monstruos al de la ciencia ficción.

El imaginario de la ciencia ficción lleva más de treinta años relacionándose con las teorías feministas en lo que Dunja M. Mohr ha llamado "distopías utópicas transgresoras", un subgénero de ciencia ficción visitado por la narrativa de autoras como Margaret Atwood. En su obra Worlds apart. Dualism and Transgression in Contemporary Female Dystopies Mohr define la unión de lo utópico y lo distópico como un modo de superación del dualismo maniqueo tradicional en la literatura de ciencia ficción (Levi, 2006). El intento de evitar las categorías binarias que Mohr explora en la literatura feminista es también un rasgo propio de la obra de Marina Núñez. En sus representaciones hay siempre una ambigüedad valorativa, un contenido distópico que a su vez quiere ser visto como posibilidad utópica. Se trata de un aspecto que hace su obra profundamente reflexiva y la libra de lo meramente ideológico. El mismo aspecto híbrido se descubre en sus iconografías de la destrucción. Por un lado representa paisajes desolados pero por otro los aborda con un gusto por la ruina y con una sensibilidad hacia lo bello ciertamente románticos.

La herramienta de exploración artística es, como se decía, el software de animación, que le permite - entre otras cosas- el juego con las texturas. Marina Núñez exprime esta posibilidad para imaginar nuevas propiedades de lo corpóreo: la fusión simbiótica de lo animal con lo vegetal, la incorporación del cuerpo al territorio y, en general, la imaginación de mundos futuros en los que lo biológico y lo técnico, la información y la carne corrigen sus límites. El hecho de que Marina Núñez no sólo trabaje con nuevas tecnologías, 
sino que reflexione sobre nuevas tecnologías, supone en su obra la fusión lograda de medio y mensaje.

Las temáticas que aborda son coherentes con un modo de trabajo introspectivo y alimentado por la lectura. Como dice Barbara Rose,

Marina Núñez bebe de las diversas disciplinas y técnicas hoy disponibles, recurriendo, en algunos casos, a imágenes encontradas en Internet. Pero su obra es profundamente personal e individual. Trabaja sola, aislada frente a la pantalla y con la ayuda de su biblioteca. La idea de comunidades virtuales interactivas en red, tan popular hoy en día, contrasta con el concepto de creatividad individual y singularidad del genio. La ideología ampliamente igualadora y democratizadora de esas comunidades se compadece mal con la imaginación romántica que exaltaba la rareza y la introspección de la inteligencia poética enajenada (Rose, 2010: 73).

Desde luego, la exploración visual de los mundos que crean o pueden crear las innovaciones tecnocientíficas es coherente con su utilización como medio artístico. Núñez lucha constantemente por vencer los límites del medio, por explorar hasta el fin sus posibilidades. Pelea con los tiempos de renderización, con los costes, etc. Por el resultado estético y, tal vez por cierta falta de maduración del medio, estas batallas recuerdan —en Marina Núñez y en otros artistas que trabajan en la misma línea- otros momentos de exploración técnica en la historia del arte: las primeras experimentaciones de flamencos e italianos con las posibilidades del óleo, las primeras tentativas de la fotografía artística, etc. La valoración de estas obras no debe olvidar esta 
circunstancia histórica de experimentación técnica en la que la artista no deja de mostrarse audaz.

\section{El ángel posthumano}

En el verano de 2008 tuvo lugar la exposición Luz y tinieblas en la Catedral de Burgos, para la que Marina Núñez realizó una serie de trabajos en torno al tema del infierno que se presentaban en diálogo con una reflexión sobre lo celestial a cargo del artista mallorquín Bernardí Roig. Luz y tinieblas era la cuarta edición del proyecto Siglo XXI: Arte en la Catedral, que había arrancado en 2005 promovido y patrocinado por Caja de Burgos en colaboración con el Cabildo Metropolitano (Núñez, Roig, 2008). Entre otras piezas, la exposición incluía unas proyecciones de distintas versiones del Ángel caído en los muros de la sala Valentín Palencia, en el claustro de la catedral (cf. abajo, reproducción autorizada por la artista).

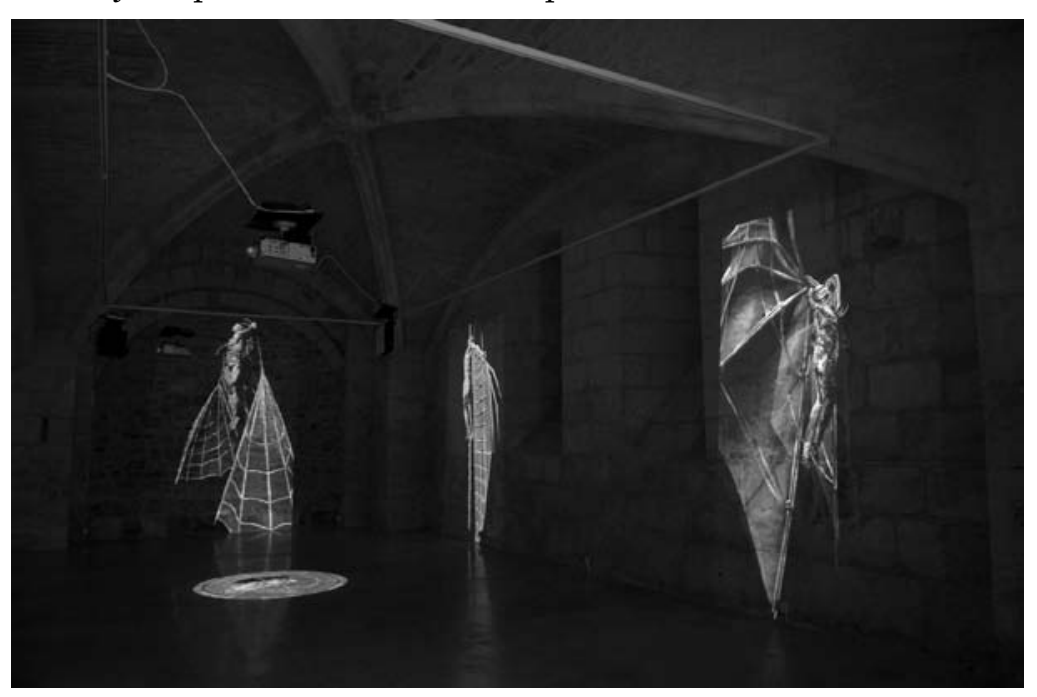

Naturaleza y Libertad. Número 9, 2017. ISSN: 2254-9668 
Las imágenes de demonios que Núñez emplea para este proyecto parten de iconografías desarrolladas por la artista en ocasiones anteriores. Por un lado se relacionan con su serie sobre Ícaro en su serie Sin título, Ciencia ficción de 2003, que supone en cierto modo una vuelta de tuerca del mito griego. Ícaro es ocasión para hablar sobre la evolución hacia una humanidad tecnológicamente ampliada. En la obra de la artista, la prótesis tecnológica quiere ser vista como algo positivo, como un modo habitual de superación de los límites que nos hace sentir su ausencia — de la prótesis- como minusvalía. Las prótesis tecnológicas en los ícaros de Núñez se naturalizan como miembros.

Desde el punto de vista formal la iconografía del ángel caído desarrollada para Burgos se relaciona, más aún que con la serie Ciencia ficción, con otra serie de obras sobre la idea de canon inspirada en el Hombre de Vitrubio de Leonardo. Canon, de 2008, al aproximarse a aspectos teóricos vinculados con el transhumanismo a partir de la cita visual de la tradición cultural del humanismo occidental, genera una simbiosis o un choque en cierto modo inquietante.

En los Ángel caído de Marina Núñez, junto a las determinaciones que impone la técnica - el dibujo por ordenador - encontramos las que añaden la imagen escogida y el concepto o tema. Por eso hay que interpretarlos no sólo en relación con el contexto de su obra y de su tiempo, sino con otros contextos más lejanos a los que pertenece la misma materialidad de la imagen, una tradición iconográfica traída y manejada por la artista que no es inocua y que configura intrínsecamente la instalación. La iconografía angélica no puede por tanto ser obviada en un ejercicio correcto de interpretación. 
La redefinición de lo angélico en el arte de vanguardia tiene capítulos tan importantes como el de la angeología de Paul Klee, cuyo Angelus Norus inspiró las reflexiones de Walter Benjamin sobre la historia, y fue con ese matiz reinterpretado por Anselm Kiefer en su Angel de la bistoria de 1989. En este, como en la mayoría de los casos del arte contemporáneo, la imagen del ángel aparece con una orientación que se aparta del terreno de lo sagrado. Puede que la simbología angélica contenga siempre también una antropología, pero en el caso del arte contemporáneo con frecuencia es sólo una antropología. Así también, probablemente, en la obra de Marina Núñez.

Sin embargo, como dice José Jiménez, "la imagen es anterior a la génesis de los lenguajes, y por eso su presencia desborda los límites de la semántica” (Jiménez, 2007: 215). Es decir, la imagen es anterior al signo. En el símbolo se produce una especie de condensación de la experiencia, siempre cambiante y fugaz, pero la imagen perdura y soporta los cambios de lo significativo. Esto implica que las imágenes son previas a lo artístico: no pertenecen al arte sino que son material del arte. Forman parte de lo dado, migran entre las culturas. Y en el viaje el ropaje simbólico se va transformando, adaptando en su función especular al entorno que las acoge.

El ángel caído es un tema de la iconografía cristiana, pero ésta a su vez se fraguó entre los siglos II y IV de nuestra era recibiendo la herencia y la riqueza visual de la cultura greco-latina. La teología cristiana de lo angélico, aunque sistematizada especialmente por Tomás de Aquino, incorpora por tanto elementos que tienen su correlato imaginativo o visual y que estaban implícitos desde los primeros siglos. En Tomás de Aquino, las jerarquías de ángeles cubren escalonadamente el abismo que separa lo humano de la abso- 
luta trascendencia de Dios, desde los niveles más cercanos a la divinidad (Tronos) a la proximidad con los hombres de ángeles y arcángeles. Los ángeles, en todos sus niveles, son individuo y especie al mismo tiempo. No deja de ser paradójico el hecho de que, aunque el tomismo deja expresamente establecido la ausencia de materia y, por tanto, la no corporalidad de los ángeles —algo no tan claro en otros autores-, sin embargo su representación es, con el correr de los siglos, cada vez más prolífica.

$Y$ es que el dominio del ángel, por lo que se refiere a su misión y tal como lo desarrolla la teología medieval, es el de la imagen, el de la visión (Jiménez, 2007: 161). El carácter incorpóreo se representa en todo caso por el carácter asexuado de la iconografía angélica que funciona como un espejo que completa la unidad escindida de lo humano. Como un aspecto inseparable de la visión, el mundo de lo angélico también es el de la mediación. En los textos sagrados del judaísmo y del cristianismo los ángeles se presentan en ocasiones como apariencias transitorias que hacen visible la divinidad trascendente y siempre son mediadores o mensajeros de la palabra, de la fuerza o de los dones de Dios.

Desde esta proliferación medieval de las imágenes angélicas damos un salto hasta el siglo XIX, que ve un renacer de la iconografía angélica en autores románticos y simbolistas como Blake, Fuseli o Flaxman. El uso decimonónico de lo angélico es tremendamente ambiguo, pero sin duda uno de los aspectos que más explota es, precisamente, el de intermediación entre lo divino y lo humano, esta vez puesto en relación con la muerte, con la idea de tránsito. Como dice María Victoria Álvarez, el carácter religioso de la representación de lo angélico va perdiendo peso en un entorno romántico y 
simbolista frente al aspecto estético, "y la naturaleza poética de estas representaciones, tal como había sucedido en el campo de la literatura en las mismas fechas, hizo del ángel un ser más humano que nunca" (Álvarez, 2015: 17).

Los ángeles recuperan su carácter eminente de espíritus mediadores, como lo son los héroes o démones griegos, cuya iconografía es tan próxima en algunos casos a la representación angélica. Por ejemplo, la del griego mensajero de los dioses Hermes, luego fundido con el egipcio Tot en Hermes Trismegisto, conocedor de ciencias ocultas y Mercurio hermafrodita, planeta de plata, el más cercano al sol, tan relacionado con la alquimia.

La figura humana alada que los cristianos habían tomado para sus ángeles procedía sin embargo más directamente de las representaciones de Eros, que Platón vincula en el Banquete a la elevación del Alma. Los ángeles, como espíritus de lo intermedio, tienen apariencia humana, pero trascienden lo humano al revestirse de alas o de otros elementos que significan el atributo de ir más allá, de estar en medio, de procurar la accesibilidad de lo inaccesible.

Todos estos elementos — la visión, la mediación, el tránsito, el dobleque están claramente en los ángeles de Marina Núñez, se vuelven sombríos por tratarse aquí de ángeles caídos. La belleza, la potencia, la elevación evitan lo blando o sentimental, buscan un carácter terrible. El vínculo del Ángel caído con sus series anteriores sobre Ícaro y el canon arriba comentadas añade matices peculiares a los demonios de la artista.

En algunas de sus exposiciones, de hecho, Núñez presenta sus ángeles caídos bajo el nombre de Ícaro, lo que permite comprender la idea de lo de- 
moniaco que la artista está manejando. Ícaro, el hijo del herrero Dédalo, meramente humano, se representa casi siempre vestido con las alas fabricadas por su padre para huir del laberinto de Minos, en el instante en que emprende el vuelo o en el momento de la caída tras atreverse a volar cerca del sol. Las alas de los ángeles de Marina Núñez tienen un carácter artificial que hace referencia a la técnica, a la trampa, al intento humano de elevarse sobre unos límites impuestos con las propias fuerzas, lo que implica el peligro de la caída y de la muerte. El relato de la caída de los ángeles por orgullo tiene un correlato secular en el rechazo de los griegos a la transgresión de los límites. Como en el caso de Prometeo, también en Ícaro, la hibris o desmesura, la desobediencia, causa la catástrofe. La reutilización moderna de los mitos griegos solía poner de manifiesto una valoración bien diversa de la idea de límite y medida, que normalmente exhibía el carácter heroico del desafío más que el aspecto moralizante del castigo. Cuando Ícaro es un equivalente antropológico del Ángel caído, esta misma transmutación afecta al concepto de lo demoniaco.

Los ángeles caídos presentados en Burgos por Marina Núñez retoman directamente la imagen leonardesca que había utilizado ya anteriormente en su serie Canon. La artista transforma el hombre de Vitruvio en ángel por el sencillo procedimiento de añadir las alas y eliminar el sexo. Las distintas versiones del Ángel caído de la artista, proyectadas en Burgos y exhibidas después en diversos formatos, representan ángeles que no vuelan, que están colgados o suspendidos en el aire, crucificados por sus alas. Las alas, de un diseño especialmente esmerado y de nuevo altamente dependiente de los dibujos de Leonardo son un alarde bellísimo de ingeniería, arqueología ima- 
ginativa del vuelo, que expresa el afán por trascender los propios límites. Recoge así la idea de la soberbia, del desafío diabólico y del castigo. Lo heroico se funde aquí con lo terrible. El castigo es intrínseco al alarde. Los ángeles humanos de Núñez quieren elevarse, fabrican unas alas a las que clavar sus brazos. La idea de sacrificio se invierte en una transmutación valorativa llena de ambigüedad que puede ser vista, como en la interpretación moderna del mito de Ícaro, como un doloroso desafío liberador (cf. abajo, reproducción autorizada por la artista).

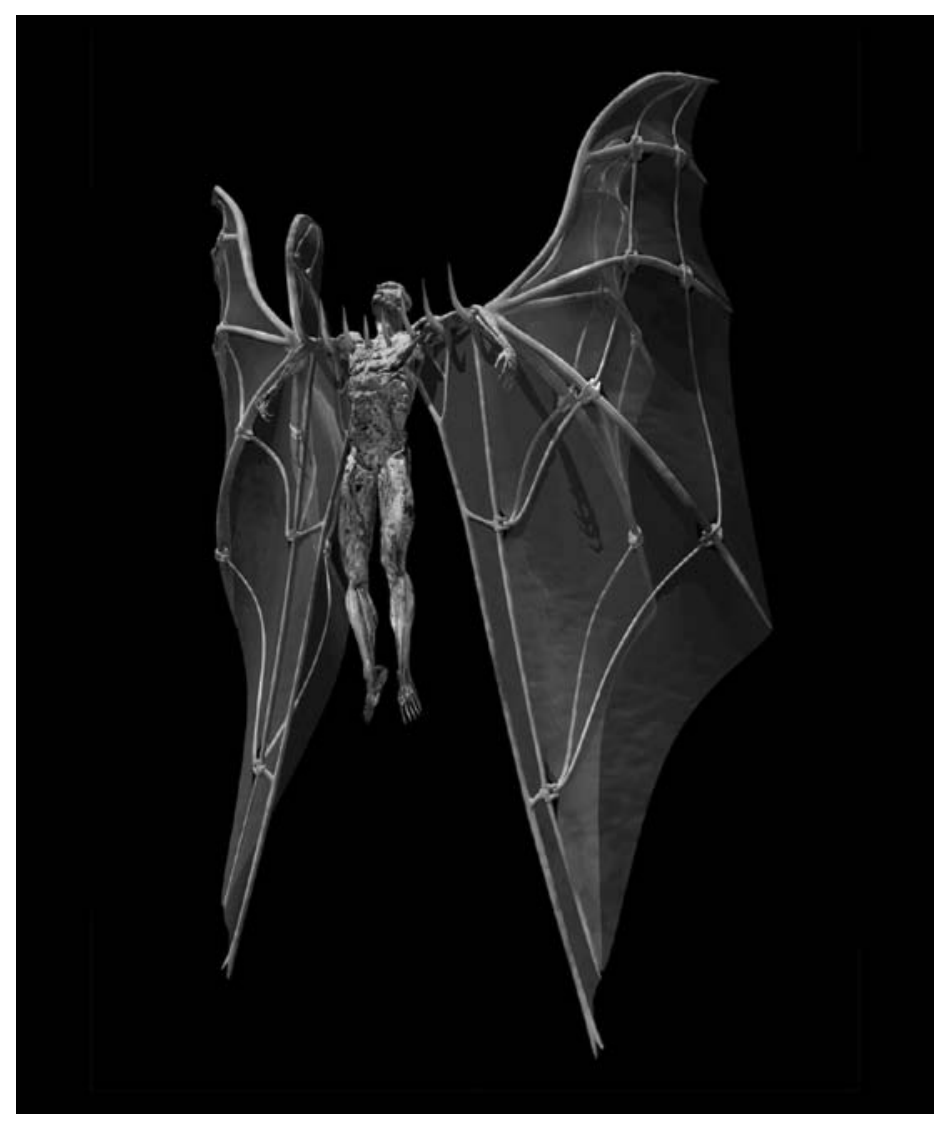

Naturaleza y Libertad. Número 9, 2017. ISSN: 2254-9668 
La relación de lo dicho con algunos temas tratados por el transhumanismo es evidente. Especialmente con los concepto de híbrido y de ciborg, tal como lo abordan autores como Latour o Haraway.

La confusión de los límites entre lo humano y lo no humano, entre lo natural y lo tecnológico, es lo propio del espacio que Bruno Latour llama "Imperio del Medio". Un reino donde se fraguan los híbridos que pueblan nuestro entorno, y que una modernidad polarizada entre el sujeto y el objeto, entre la sustancia extensa y la sustancia pensante, no nos habría dejado ver. En el reino oculto del que nacen los híbridos se da, según Latour, ese continuum naturaleza-cultura que propugnan los defensores de mostrar las redes, el magma de los procesos, en el que se gesta lo que luego la labor purificadora de la diferenciación permite clasificar o definir. De ese espacio, precisamente por su carácter oculto, surge lo que el mismo Latour llama "monstruos":

Embriones congelados, sistemas expertos, máquinas digitales, robots con sensores, maíces híbridos, bases de datos, psicotrópicos entregados a pedido, ballenas equipadas con radiosondas, sintetizadores de genes, analizadores de audiencias. [...] Todo ocurre como si ya no hubiera los suficientes jueces y críticos para tratar los híbridos. El sistema de purificación se atasca (Latour, 2007: 84).

Según afirmaba Latour en el ya lejano 1991, se hacía necesario buscar sistemas de representación que hicieran visibles los procesos: "Habrá que aminorar, desviar y regular la proliferación de los monstruos representando oficialmente su existencia”, afirma (Latour, 2007: 30). 
Lo monstruoso en la obra de Núñez no hace necesariamente referencia a la hibridación, pero sí a lo no canónico. Para ella lo híbrido es sólo una forma más de la diferencia:

Todos tenemos algo de monstruos: medidas imperfectas, procesos de cambio, desechos corporales. Incluso la mezcolanza: los trasplantes de órganos humanos o animales, la ingeniería genética y la creciente incorporación de ingenios artificiales han hecho de los cuerpos del siglo XX entidades decididamente mixtas (Núñez, 2001).

La de monstruoso es una categoría cambiante, que se desplaza con los vaivenes y ampliaciones del canon humano:

Los nuevos monstruos sólo lo son desde nuestra perspectiva: si, por poner un ejemplo, un cuerpo de piel quitinosa y forma de pulpo cabezón es lo que le conviene al orden social que se avecine, lo monstruoso será aferrarse a un canon desfasado. Porque lo monstruoso es siempre lo que se opone a las normas establecidas, lo que desafía un sistema, y su apariencia cambia con la ideología dominante (Núñez, 2001).

Por eso en su trabajo explora la artista los miedos, como un modo de interiorización de las normas sociales. Así sucede, por ejemplo, en su exposición de 2012 para la Capilla del Museo Patio Herreriano de Valladolid, en línea con la exploración de las tinieblas que está también presente en el encargo de la catedral de Burgos. En el título El infierno son nosotros funde la frase "L'enfer c'est les autres" de Sartre con la inversión del giro "je est un autre" de Rimbaud. La representación de una idea secularizada del infierno sirve a 
Marina Núñez para hablar del miedo. No del miedo al Infierno, sino del infierno que es el miedo mismo.

El mito moderno del ciborg (cybernetic organism), que es a la vez un modo de representación del híbrido - como reclama Latour- y una configuración que cuestiona la definición de lo humano invadió el terreno de la narrativa en ciencia ficción en las últimas décadas del siglo XX. Pronto, desde las visiones de la literatura, el cine o el comic, teñidas de negatividad, pasó también al pensamiento antropológico postmoderno de autores que buscaban una definición de lo humano que permitiera la inclusión y la consideración positiva de lo queer (raro o monstruoso). Así por ejemplo, Donna Haraway, en su Manifesto for Cyborgs de 1985 reivindica que a la continuidad entre lo humano y lo animal de las visiones evolucionistas del pasado se debe añadir, para visualizar el futuro, la continuidad entre lo humano y la máquina. Busca Haraway un pensamiento evolutivo que desafíe las fronteras, que trasgreda las esencias.

Una propuesta igualmente feminista y tecnófila, pero con tintes diversos, procede de la teoría del pensamiento nómada de Rossi Braidotti. Desde un feminismo de la diferencia, en cierto modo opuesto al feminismo de la igualdad de Judith Butler (en cuya tradición se inserta Haraway), la europea Braidotti se refiere a la capacidad específicamente humana de estar en un sitio y a la vez fluir. Próxima a Deleuze, Braidotti reduce lo humano a lo que ella llama "subjetividad nómada".

El pensamiento de Braidotti viene al caso del trabajo de Núñez porque aquella se declara "antihumanista", queriendo expresar con ello no una oposición al hombre sino a la definición moderna de lo humano. A aquel 
humanismo moderno que despuntó con el trabajo de los humanistas del Renacimiento y que tal vez ha hallado su mejor representación en el hombre de Vitrubio. La iconografía leonardesca de Marina Núñez se puede entender también como el modo de nombrar el humanismo antes de transgredirlo.

En el mito clásico de Ícaro se evocaban el riesgo de la caída, el fracaso, la muerte y el reconocimiento de las cadenas del cuerpo, de un límite que no se puede traspasar impunemente. Marina Núñez, al pensar el ciborg desde lo demoníaco en su correlato antropológico Ícaro, no puede evitar las connotaciones terribles que acompañan a ambos. En el entorno tecnófilo del transhumanismo, al que Núñez se siente afín, hay un esfuerzo por eliminar ese tipo de connotaciones. En el posthumanismo de Braidotti, por el contrario, la muerte es lo positivo, es el último rasgo de humanismo que merece la pena conservar. En esto Braidotti se separa de manera expresa de los Ícaros modernos que, como el científico Kurtzwell, buscan en la inteligencia artificial una especie de perpetuación de la vida, esto es, lo transhumano, diverso de lo posthumano que ella postula (Braidotti, 2015).

Es interesante que los ícaros-ángeles caídos de Marina Núñez muestran de qué modo la tradición persiste en la imagen hasta el punto de traicionar el pensamiento. De hecho, como se ha visto, el mito de Ícaro no es apropiado para representar el continuum naturaleza-cultura del que habla Latour porque nos dejan anclados en el dualismo, reemplazando la negatividad de la materia por la negatividad de la técnica.

A pesar de que en la obra de Marina Núñez se pueden encontrar indudables referencias tecnófilas a lo posthumano y su gusto por los híbridos es claro en algunos de sus trabajos, como sus obras sobre la simbiosis, el mito de 
Ícaro y, especialmente, su transformación en ángel caído son extrañamente tecnófobos. La propia artista lo reconoce, y afirma:

Si fuera más racional quizá sería más capaz de proponer imágenes tecnófilas, porque me interesa mucho la idea de Haraway de considerar el ciborg como un modelo apasionante de subjetividad. Esa idea me ha animado a retomar algunas imágenes que, en principio, solemos entender como espeluznantes, para proponerlas como constructivas, incluso como placenteras (por ejemplo, la unión con lo otro, lo alien, entendida como simbiosis y no como invasión o contaminación) (Tejeda, 2011).

En efecto, es su no-racionalidad, el poder de su juego imaginativo, lo que prima en sus obras. Y la imagen se impone con sus propios valores. Por eso continúa la artista,

Mi visión del mundo es trágica, las imágenes que siempre me han atraído son las más oscuras, y me cuesta que las mías no sean por tanto dramáticas, catastróficas, desoladas. Es un esfuerzo para mí proponer escenas, aún inquietantes, más amables o esperanzadoras, y en cuanto me dejo llevar me sale el tono siniestro, aun considerando que quizá políticamente fuera más útil, o incluso más interesante, la otra actitud (Tejeda, 2011).

$\mathrm{Y}$ es que las imágenes, como la piedra, son un material previo duro, terco. No es fácil para el artista honesto, no manipulador, cambiar de signo lo terrible. Los tiempos de maduración de los símbolos son lentos. Pero la lucha del artista por pensar la imagen recibida es fructífera también por darle de nuevo 
voz en un tiempo diverso, en medio de una nueva sensibilidad que se comprende mejor cuando se escucha a sí misma rumiar la tradición.

\section{Bibliografia empleada}

M. V. Álvarez Rodríguez, "Iconografías angélicas de los siglos XIX y XX en el Cimitero Acatolico de Roma: psicopompos, triunfantes, dolientes y seductores”, en El futuro del Pasado, 2015 (6), pp. 215-232.

R. Braidotti, Lo posthumano, Gedisa, Barcelona, 2015.

J. Jiménez, El ángel caído, Galaxia Gutenberg, Barcelona, 2007.

B. Latour, Nunca fuimos modernos. Ensayo de antropología simétrica (1991), Siglo XXI, Buenos Aires, 2007.

B. Levy, "Worlds Apart? Dualism and Transgression in Contemporary Female Dystopias by Dunja M. Mohr", en Science Fiction Studies. Vol. 33, No. 3, nov., 2006, pp. 536-539.

P. Mayayo, "Charcot reinterpretado", en Jano Medicina y Humanidades, no 1.651, 11-17 de mayo de 2007, pp. 52-54.

M. Núñez y B. Roig, Siglo XXI : arte en la Catedral de Burgos : luz y tinieblas. Catálogo de exposición. (Textos de Rafael Sierra, Estrella de Diego y Matías Vicario), Caja de Burgos, Burgos, 2008.

M. Núñez, "Es el tiempo de Prometeo”, en Artyco, no 11, invierno 2001, pp. 53-55.

B. Rose, "El mundo está demasiado con nosotros", en Núñez, Marina, Demasiado Mundo, catálogo de exposición. Generalitat Valenciana. Centre del Carme, Valencia, 2010. pp. 37-75.

I. Tejeda, "Marina Núñez o la construcción del cíborg. Un discurso multimedia entre la utopía y la distopía”, en Icono 14, revista digital, no 18, 2011, Año 9 Vol. 1 -Mujeres y tecnología, pp. 1-19.

Nieves Acedo

nacedo@unav.es 
